\title{
COMPULSORY ADMISSION IN FIRST EPISODE PSYCHOSIS
}

S. Vilas Boas Garcia ${ }^{1}$, I. Pinto ${ }^{1}$, T. Teodoro ${ }^{1}$, R. Lopes Fernandes ${ }^{1}$, R. Mateiro ${ }^{1}$, M. Avelino ${ }^{1}$, M. Martins ${ }^{1}$, J. Salgado ${ }^{1}$.

Centro Hospitalar Psiquiátrico de Lisboa, CHPL, Lisbon, Portugal

\section{Objectives}

The aim of this study is to compare sociodemographic and clinical variables in compulsory and voluntary admission in patients with First Episode Psychosis (FEP).

\section{Background}

Some FEP patients have their first contact with mental health services when they are admitted to the hospital. Compulsory Admission has several sociodemographic and clinical factors.

\section{Materials and Methods}

A total of 110 patients with FEP admitted between 01/07/2016 and 31/12/2017 to "Serviço de Estabilização e Tratamento de Agudos" of Lisbon Psychiatric Hospital were included.

The 10th revision of the International Statistical Classification of Diseases and Related Health Problems (ICD-10) was used for diagnosis. Data related to clinical and sociodemographic characteristics were collected retrospectively from case notes. The sample was divided into 2 groups: Compulsory Admission (CA) and Voluntary Admission (VA).

\section{Results}

CA group represented $46 \%$ of the sample. Mean age was 33 for both groups. Male gender was $59 \%$ for the CA group and $49 \%$ for the VA group. Migrant patients were $32 \%$ in VA group and $31 \%$ in CA group.

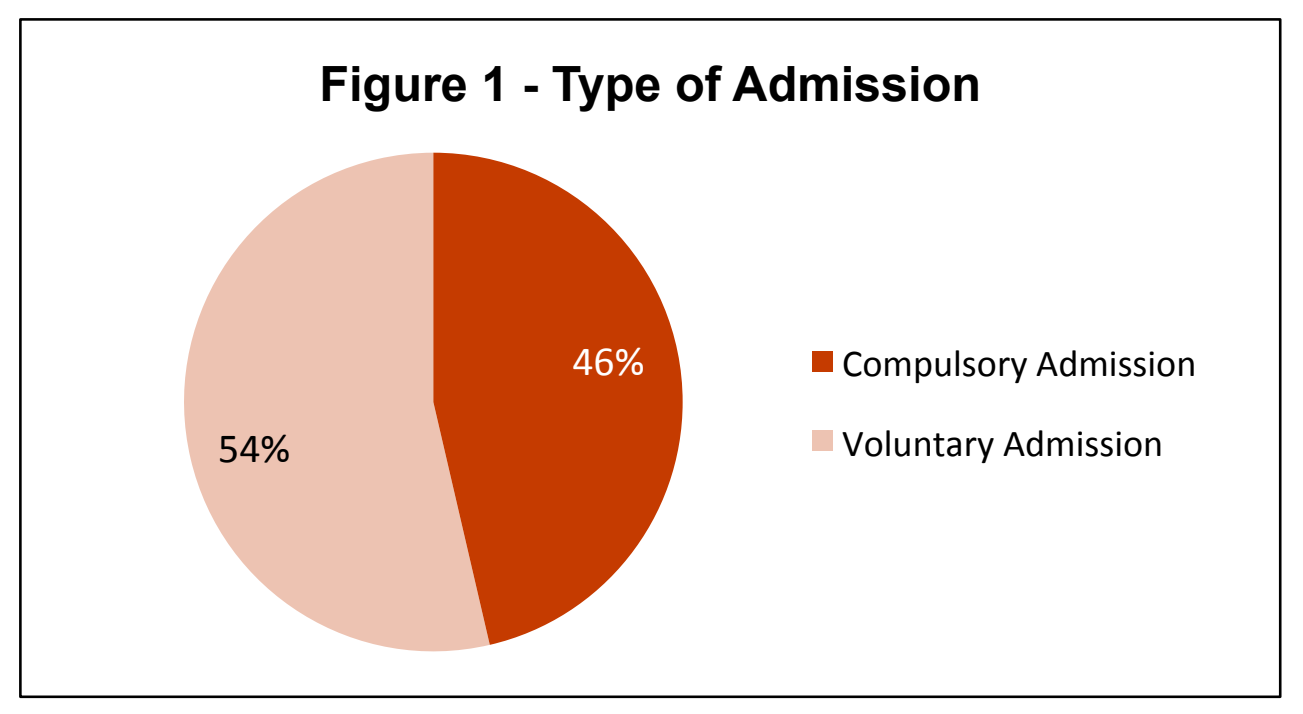

\begin{tabular}{|c|c|c|c|c|}
\hline \multirow{3}{*}{ Gender } & & $\begin{array}{l}\text { Sample } \\
(N=110)\end{array}$ & $\begin{array}{c}\text { Compulsory } \\
\text { Admission } \\
(\mathrm{N}=51)\end{array}$ & $\begin{array}{c}\text { Voluntary } \\
\text { Admission } \\
(\mathrm{N}=59)\end{array}$ \\
\hline & Male & $54 \%(N=59)$ & $59 \%(\mathrm{~N}=30)$ & $49 \%(\mathrm{~N}=29)$ \\
\hline & Female & $46 \%(N=51)$ & $41 \%(N=21)$ & $51 \%(\mathrm{~N}=30)$ \\
\hline \multirow[t]{2}{*}{ Age } & Mean & 33 & 33 & 33 \\
\hline & Married & $19 \%(\mathrm{~N}=21)$ & $18 \%(\mathrm{~N}=9)$ & $20 \%(N=12)$ \\
\hline \multirow{3}{*}{$\begin{array}{l}\text { Marital } \\
\text { Status }\end{array}$} & Divorced & $11 \%(\mathrm{~N}=12)$ & $8 \%(N=4)$ & $14 \%(N=8)$ \\
\hline & Single & $67 \%(N=74)$ & $73 \%(N=37)$ & $63 \%(N=37)$ \\
\hline & Widowed & $2 \%(\mathrm{~N}=2)$ & $2 \%(N=1)$ & $2 \%(N=1)$ \\
\hline \multirow{7}{*}{$\begin{array}{l}\text { Education } \\
\text { Level }\end{array}$} & N.A. & $1 \%(\mathrm{~N}=1)$ & $0 \%(\mathrm{~N}=0)$ & $0 \%(\mathrm{~N}=0)$ \\
\hline & Anaphabet & $2 \%(N=2)$ & $2 \%(N=1)$ & $1 \%(N=1)$ \\
\hline & $1^{\text {st }}$ Cycle & $7 \%(N=8)$ & $4 \%(N=2)$ & $10 \%(\mathrm{~N}=6)$ \\
\hline & $2^{\text {nd }} / 3^{\text {rd }}$ Cycle & $42 \%(\mathrm{~N}=46)$ & $43 \%(N=22)$ & $41 \%(\mathrm{~N}=24)$ \\
\hline & Secondary & $19 \%(\mathrm{~N}=21)$ & $14 \%(\mathrm{~N}=7)$ & $24 \%(N=14)$ \\
\hline & Higher & $15 \%(\mathrm{~N}=17)$ & $18 \%(\mathrm{~N}=9)$ & $14 \%(\mathrm{~N}=8)$ \\
\hline & N.A. & $0 \%(N=0)$ & $20 \%(N=10)$ & $10 \%(\mathrm{~N}=6)$ \\
\hline \multirow{5}{*}{$\begin{array}{l}\text { Employment } \\
\text { Status }\end{array}$} & Employed & $30 \%(\mathrm{~N}=33)$ & $28 \%(N=14)$ & $32 \%(\mathrm{~N}=19)$ \\
\hline & Unemployed & $50 \%(N=55)$ & $49 \%(N=25)$ & $51 \%(\mathrm{~N}=30)$ \\
\hline & Student & $14 \%(N=15)$ & $12 \%(N=6)$ & $15 \%(\mathrm{~N}=9)$ \\
\hline & Retired & $5 \%(N=5)$ & $8 \%(N=4)$ & $2 \%(N=1)$ \\
\hline & N.A. & $2 \%(N=2)$ & $4 \%(N=2)$ & $0 \%(\mathrm{~N}=0)$ \\
\hline
\end{tabular}

Unspecified Nonorganic Psychosis (F29) was the diagnosis in $29 \%$ of patients from CA group and $41 \%$ in VA group. Mental and Behavioural Disorders due to Psychoactive Substance Use (F10-F19) were more frequent in the CA group (27\%) than in the VA group $(7 \%)$. Median duration of untreated psychosis was 39 weeks in both groups. Median length of stay was 21 days for CA group and 22 days for VA group.

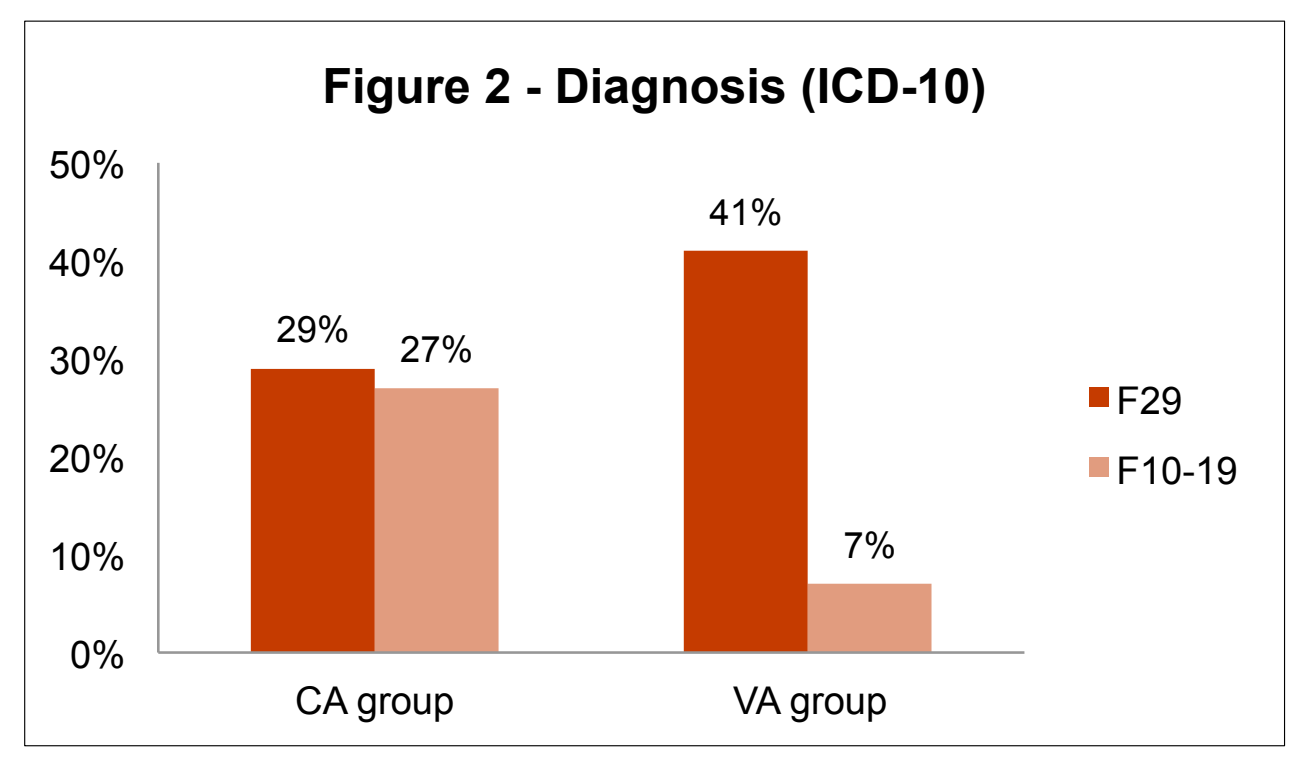

\section{Conclusions}

Male gender was more frequent in the CA group and female gender was more frequent in the VA group. Disorders related to substance use were more frequent in the CA group.

This study was conducted in a single service which limits generalizing the findings to other services and other clinical groups. Further larger studies investigating acute psychiatric patients characteristics would be important to better understand this population. 